\title{
AUDIOVISUAL TECHNOLOGY AND IMPLICATIONS FOR TEACHING
}

\author{
Yiran Li, M.A. \\ $\mathrm{PhD}$, Cheongju University, Cheongju, South Korea \\ Branko Medic \\ Doctor of Science, Manchester University, United Kingdom
}

\begin{abstract}
Previous studies have indicated the potential for incidental vocabulary learning through viewing television. The assumption has been that the imagery in television helps learners acquire vocabulary because when they hear an unfamiliar word, the on-screen images provide semantic support. However, the extent to which imagery in authentic television supports learners in this way is unclear. This study examines 90 target words occurring in single seasons of television, and the degree to which their aural occurrence matched the presentation of a potentially supporting image. Results indicate differences in the way imagery supports potential vocabulary learning in documentary television compared with narrative television, and that this supporting imagery occurred concurrently with the aural form more often in documentary television. Research and pedagogical implications are discussed in detail.
\end{abstract}

Key words: vocabulary, television, imagery, video, incidental learning.

Cite this Article: Yiran Li, M.A. and Branko Medic, Audiovisual Technology and Implications for Teaching, International Journal of Management (IJM), 11(6), 2020, pp. 2193-2198.

http://iaeme.com/Home/issue/IJM?Volume=11\&Issue $=6$

\section{INTRODUCTION}

Since many years, a number of educational reforms have been introduced in an effort to provide the world of pedagogics with some authentic teaching and learning techniques. Education and technology are part and parcel and can never be isolated in order to introduce and enhance the learning aspects of education. The use of audio visual aids particularly videos is now being appreciated and selected by the instructors as a medium of teaching the foreign language so as to achieve the targeted learning goals. Videos are a form of input that can exceptionally stimulate and increase the learning abilities of students as they are a rich source of input when it comes to the teaching of a second or foreign language to the students. This new trend of being more concerned about the teaching ways coupled with the use of technology has brought a revolutionary change in the field of education. Audiovisual technology (AT) is the current 
reality of educational technologies being employed to serve the purpose of learning and stimulate the foreign language acquisition.

Videos can be defined as delivering information, either educational or non-educational, about a certain subject in an audio visual context. Videos permit the learners to understand a language at the grass root level as they come across the native speakers of language not only speaking in different accents of the same language but also the expression words, postures and body language of them (Lin, 2014; Rodgers, 2018). The students learn about the different language aspects as well as the interaction dynamics when videos are used as instruction medium. This innovation in the traditional formal set up of the classroom can led to the development of extra ordinary learning attitude in learners and can teach the students to interact well among themselves. Using a visual aid, exploits both audio and visual memories of the learners and modern principles of science support the fact that humans are more interested in pictorial representation of a subject rather than the traditional formal lectures. It also aids learners to reflect and memorize the knowledge for long period of time thus promoting its long term maintenance (Alava \& Etévé, 1999; Andrade \& Spinillo, 2013; Friedrich, 2001; Wolfs, 2007). Using videos can change the learning experience entirely before and after the completion of a task in classroom.

To investigate more useful techniques and methods of modern technology and their usefulness in the field of pedagogics, this research focus has been selected because being a foreign language instructor I personally believe that now it the traditional pedagogical methods must be changed or get tangled with technological advances to enhance the learning attitude in the students. The acquisition of this era in context of learning a foreign language needs to be translated into a dimension where technology can play an ever enchanting and charismatic role to help produce a generation that possess skills as well as latest knowledge imparted by the latest means of teaching. Utilizing videos with the correct and purposeful content in foreign language classes is a whole new world of learning and using the audio visual aids in education sector and therefore this subject is taken under discussion in this research to unveil the hidden and yet untouched aspects of using videos in foreign language learning processes. This research will definitely make a remarkable contribution in the pedagogics and may led to the reforms in the traditional learning setups that can bridge the gap between learning and professional skills.

\section{LITERATURE REVIEW}

Researchers have been exploring for the new technologies as well as their effectiveness and acceptance regarding the field of education that can fit in the modern era of advancement. The formal language learning by traditional methods of class room that has been beneficial in early times is now no more appreciated by the learners as well as the instructors. For this purpose, a number of surveys and research studies are reported in literature and one of the emerging technologies in this field is the use of audio visual technology. Audiovisual technology (AT) is a domain of technology that utilizes both audio and visual pathways in humans for the perception of information (Pisarenko, 2015). It has been analyzed that the use of videos engage students in the process of learning more effectively. They can learn the language as well as its other aspects like how to use that language formally either for communicating/interacting with others or for writing purposes. Literature supports the implication of videos in teaching a foreign language as they are reported to be a rich source of language, vocabulary and also supports the learners to make use of that language in written or spoken mode (Hemei, 1997).

Another crucial point undertaken by practitioners, to be considered regarding the use of videos, is their effect on the task completion ability of students. The constructivist theory of learning and methodology of teaching a language emphasizes the task based learning of a language (Ellis, 2003). This theory has been based on the conventional PPP approach i.e. the 
presentation process of a language, its practice and performance of the learners in the assigned tasks (Long \& Crooks, 1991). Videos provide the students with the most realistic mode of learning a language and can ultimately help them in completing a task regarding that language (Arthur, 1999). Videos assist in language learning as well as enhance the understanding and usage of learned language because students are more attracted towards the visual presentation. The learners can better perform in the tasks assigned by their tutors that can either be in the form a written assignment or a dialogue discussion between the learners in that particular foreign language.

It has also been reported in a survey that video films engage the students in a more effective and interesting way and it might be due to the visual involvement of learner instead of the auditory one (Canning-Wilson, 2000). Researchers have also addressed the importance of content and duration of videos in this regard. The content must be informative and latest in every aspect while the duration depends upon the level of advancement of language course i.e. less advanced students are more inclined towards short videos because they only need to learn the basics of a foreign language as compared to the advanced level students. Language videos with subtitles and captions tremendously improve the scores of comprehension tasks of the learners (Herron, Hanley \& Cole, 1995). The course contents of language learning when coupled with the videos, enhance the ability of students to retain the knowledge and grammatical aspects of language as well and improve their task performance in the class (Herron, 1994).

This research puzzle has been focused to find out the aspects that are important yet not extensively been discussed and analyzed in the previous surveys and studies. In relation to the task performance ability of learners, the involvement of videos in foreign language learning needs to be further explored and discussed by the practitioners and experts so that the hidden facts can be unveiled about their influence on the performance of learners in classroom.

\section{RAISED AWARENESS}

Literature is studded with a number of case studies, analysis and researches that support the use of visual aids in foreign language learning. Every research discusses AT under multiple different perspectives and then rules out the effectiveness and acceptance of that particular perspective by observing the viewpoint of both instructor and learner. Audiovisual technology has emerged as a non-traditional technique of teaching years ago but its practical implications in pedagogics are yet to be discovered. The perspective being focused in this research is the effect of using videos on the task performance of learners. Prabhu was the pioneer of task based foreign language learning who coined and then published the concept of task based teaching and learning (Wei, 2004). Both these concepts are now being integrated in pedagogics to make foreign language learning more constructive and beneficial for students. The idea of illustrative pedagogics has revolutionized the process of teaching and learning. Also it has impacted positively upon the learning abilities of students, their enthusiasm for a foreign language and then its use afterwards the completion of language course.

Videos has proven to be of immense help in teaching foreign language as they involve the students not only audiovisually in learning process but also engage them emotionally and psychologically by observing the phonetics of language being observed in video clips. They are a powerful source of delivering the content to be discussed in the span of a whole class in just a few minutes. Regarding task performance, videos can help students with better understanding of comprehension as well as spoken mode of language. It has been observed and analyzed that foreign language acquisition courses involving the use of visual technology are a potent source of improving the task performance in students as compared to those courses that follow the traditional teaching methods. Videos touch every aspect of a language and can help students 
preserve the information for a longer period of time in their memory. They assist students to learn the practical, natural and functional utility of a non-native language in a more purposeful way (Lin, 2009).

As a foreign language practitioner and working with young students I tend to be more reflective and innovative when it comes to the introduction of reforms in the teaching methods. Technology has become the need of hour in the real world pedagogics and being an enthusiastic instructor I prefer the integration of technological advances in education sector. The literature that has been discussed in earlier sections of this article has enlightened my views about the employment of videos in foreign language acquisition and their diverse positive and strong effects on learners i.e. their psychological, emotional, auditory engagement in the course and resulting improvement in understanding the true meaning and use of a second language by upgrading their performance in the class. Literature has compared the task performance before and after the video watching in language learning courses and the results showed to be more favorable in case of involvement of videos in learning a foreign language. However, no matter which technology is being used, instructors and experts of this field must set some rules and principles to follow in order to make best use of that technology to get the required learning outcomes.

\section{PEDAGOGICAL INTERVENTIONS}

Video films, clips and other types of visual technology such as animation is an advantageous tool in foreign language learning and can remarkably enhance the learning potential and performance of students. Videos provide the realistic language input as they as designed directed for the native speakers (Katchen, 1996). They are easy to use i.e. the instructor can start and stop a video several times at any point during the class whenever he wants. A clip of short duration from a whole video can be rewound several times and can be used for the intensive studies on some important points of the lecture. It is also feasible in some situations to run a video in slow motion, with or without sound as per the capacities of students to absorb the language input. They can be termed as real time control points of a language learning class. Learning a language while watching a video, the learner can concentrate on a language in detail and can predict the reply by understanding what has been said and performed earlier in the previous sequence of the video. Traditional language learning courses only convey the meaning of language to the learner but using videos assist them in interpreting the attitude of performer by providing visual clues. It is an enjoyable source of learning that is completely different experience from just studying the course books of a foreign language.

On the other hand, using videos also has some critical and challenging points to be considered while using them in class rooms. Some of the students may take them as a burden as they have a rich and intense language learning material. Learners may not appreciate their use because of the fear of technology or they might be more comfortable with the traditional teaching setup due to little technological background. The cost and their maintenance might be the issues of instructors for their use in the pedagogics. Instructors should be well trained and familiar with the usage and selection of purposeful videos regarding the foreign language learning. Using any kind of technology in pedagogics does not mean at all that it can replace the teacher. Instructor is as important as the use of technology (primarily videos in this case) in foreign language acquisition. The instructor must play the role of an organizer, controller and participant while using a video film as an aid in teaching process. He should also be a prompter to explain any ambiguity of learners while watching videos and should plan the tasks accordingly in order to make sure that the learners are responding to the use of visual aid efficiently. 
No matter which technology the practitioners prefer to use, they must consider the whole scenario of learning as well as abilities of the students in understanding and acceptance of the technique being used. Therefore, using a technological advancement can be an aid as well as additional responsibility on instructor to make its use effective and successful.

\section{CONCLUSION}

Videos offer the learners a chance to improve their interpretation and understanding of a foreign language in a comprehensive manner. The purpose of teaching a foreign language is not mere the completion of course contents and targets but to facilitate them with proper conditions of practically learning and using a language for communicative purposes. The advantages of using visual aids particularly videos in foreign language teaching and acquisition are numerous. The implication of videos in language learning has bridged the distance between learning and real world. Coupled with effectively designed tasks, videos can play an important role in real time practical application of learned language. It allows the learners to actively participate and grasp the roots of a foreign language at their own pace.

It is now highly being recommended to use the visual technology in teaching a foreign language because it practically allows the learners to improve their task performance. Learner is the central focus of pedagogics and every innovation to be explored in this field must be in accordance with the ease of learner and should be beneficial for him both in personal and practical perspectives. However, more research has yet to be conducted on using audiovisual aids and designing of tasks in pedagogics to make a powerful impact and revolution in foreign language acquisition.

\section{REFERENCES}

[1] Alava, Séraphin, and Etévé, Christiane (1999). Note synthèse.Revue Française de Pédagogie 127: 119-64

[2] Arthur, P. (1999). "Why use video? A teacher's perspective", VSELT 2:4: 4

[3] Christine Canning-Wilson (2000). Research in Visuals. Video Special Interest Group at the International TESOL Arabia 2000 Conference. Arabia

[4] Ellis, R. (2003). Task-based language learning and teaching. Oxford: Oxford University Press.

[5] Friedrich, Janette (2001). Philosophie, psychologie et pédagogie: Un ménage à trois. In Le Pari des Sciences de L'éducation. Paris: De Boeck Superieur, p. 57

[6] Hemei, J. (1997). Teaching with Video in an English Class, Journal of English Teaching Forum, vol.35-2, pp 45-47

[7] Herron, C. (1994). An investigation of the effectiveness of using an advance organizer to introduce video in the foreign language classroom. Modern Language Journal, 190-198.

[8] Herron, C, Hanley, J. and S. Cole (1995). A comparison study of two advance organizers for introducing beginning foreign language students to video. Modern Language Journal, 387-394.

[9] Katchen, J.E. (1996). Using authentic video in English language teaching: Tips for Taiwan's teachers. Taipei: The Crane Publishing Company, Ltd Video in ELT-Theoretical and Pedagogical Foundations. Proceedings of the 2002 KATE (The Korea Association of Teachers of English) International Conference (pp. 256-259) 
[10] Lin, Z. (2009). Task-based Approach in Foreign Language Teaching in China: A Seminar Paper Research Presented to the Graduate Faculty, University of Wisconsin-Platteville. Available online http://minds.wisconsin.edu/bitstream/handle/1793/34571/Zhu,\%20Lin.pdf.txt?sequence=3, accessed July 10, 2010.

[11] Long, M., \& Crookes, G. (1991). Three approaches to task-based syllabus design. TESOL Quarterly, 26(1), 27-56.

[12] Pisarenko, Veronika. 2015. Informational and Technological Support of Foreign Language Training in High School. Paper presented at 9th International Conference on Application of Information and Communication Technologies (AICT), Rostov-on-Don, Russia, October 1416

[13] Rodgers, M.P.H. 2018. The images in television programs and the potential for learning unknown words. ITL-International Journal of Applied Linguistics 169, no. 1: 191-211.

[14] Wei, Y. H. (2004). A Teaching Research on Task-based Approach. East-China Normal University Publisher.

[15] Wolfs, José-Luis (2007). Méthodes de Travail et Stratégies D’apprentissage. Paris: De Boeck Supérieur. 